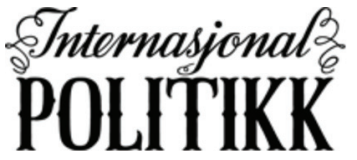 \\ SKANDINAVISK TIDSSKRIFT \\ FOR INTERNASJONALE STUDIER
}

Årgang 75, Nummer 1, side 13-20, 2017, ISSN 1891-5580, www.tidsskriftet-ip.no, Publisert mars 2017

FoKUS: SkANDINAVIA OG USA

\section{«Drømmen om Amerika» - en selvoppfyllende profeti}

\author{
Tormod Heier \\ Forsvarets høgskole
}

Etter den russiske annekteringen av Krim i 2014 har Norge, Sverige og Danmark lagt seg tettere opp til amerikansk sikkerhetspolitikk. Det er flere eksempler på dette. Ett eksempel er ratifiseringen av den svenske vertslandsavtalen med NATO i mai 2016. Med dette kan Riksdagen på kort varsel godkjenne amerikanske overflygninger, «øvelser» og operasjoner i Østersjøregionen fra eget territorium (Sveriges Riksdag 2016). Et annet eksempel er Norges noe mer utilslørte «invitasjonspolitikk» overfor USA. På like kort varsel kan mer enn 330 amerikanske marinesoldater fra baser og forhåndslagre på Værnes møte russiske styrker 400 kilometer unna, i Østersjøregionen. Et tredje eksempel er danske hærstyrker i Baltikum. I tråd med USA-initiativet Enhanced Forward Presence opererer omlag 200 soldater i fire fremskutte NATObataljoner langs den estiske grensen til Russland (Forsvarsministeriet 2016).

Den kalde krigens logikk om at Skandinavia var best tjent med selvpålagte restriksjoner er dermed i endring. Norske, svenske og danske beroligelsestiltak rettes ikke lenger mot Russland slik brobyggings- og lavspenningspolitikken under den kalde krigen la opp til. I stedet rettes tiltakene mot baltiske og østeuropeiske NATO-land. Dette er stater som tidligere var plassert i Russlands «bakgård», men som i dag er del av et bredere amerikansk ønske om å få «Europe Whole and Free» (Bush 1989). Den såkalte «nordiske balansen» (Eriksen 1999; Andrén 2009) som skulle holde stormaktene på armlengdes avstand er dermed under press. Ganske så forsiktig har pendelen svingt fra skandinavisk beroligelse til en mer outrert form for avskrekking. Noe av poenget er å gjøre overgangen fra nasjonal til amerikansk sikkerhet så «sømløs» som mulig. Med dette kommer også «drømmen om Amerika» nærmere, ikke bare i populærkulturen men også i «sikkerhetskulturen». 


\section{Hva forklarer USA-dreiningen?}

Mange teorier kan brukes for å forstå den skandinaviske dreiningen. Den geopolitiske skoleretningen til Halford Mackinder vektlegger territoriets betydning (Mackinder 1962). Med et mer selvhevdende Russland øker også den strategiske «tomteverdien» av norske, svenske og danske landområder. Dette gjør at selv nøytrale stater som Sverige, riktignok på subtilt vis gjennom NATO, søker tettere samarbeid med USA (Mehta 2016). Også Norge legger seg nærmere USA. Trøndelags geografiske betydning blir mer relevant for amerikanske styrker, som med høy reaksjons- og forflytningsevne kan møte russiske styrker i Østersjøen (Schogol 2016). Når både USA og Russland ser skandinavisk territorium som mulige springbrett for amerikanske operasjoner $\mathrm{i}$ regionen får dermed geopolitikken økt forklaringskraft. Således påvirkes også de skandinaviske småstatenes strategier i balansen mellom avskrekking og beroligelse.

Mackinders Hartland-teori er også nært beslektet med Hans Morgenthaus og Kenneth Waltz realpolitiske tankegang (Morgenthau 1948; Waltz 1979). Med en logikk der «the strong do what they can and the weak suffer what they must» (Thucydides 1951: 331), øker den militære avhengigheten til USA. Mer lydhørhet og forståelse for sær-amerikanske syn og påtrykk - om at «makt må møtes med motmakt» - er derfor naturlig. Selv om det skandinaviske samarbeidet først og fremst kanaliseres gjennom NATO er det vanskelig å se bort ifra en ting: uten USAs finansiering på nærmere $75 \%$ ville det ikke vært et felles realpolitisk maktsentrum å søke hjelp i. Spesielt ikke når omgivelser preges av en gradvis re-nasjonalisering og forvitring av kollektive forsvars- og sikkerhetsmekanismer. Når anarkiet kommer nærmere søker også småstatene tettere inn mot de «sterkeste guttene i klassen» (Walt 1987: 23-26).

Med dette får realismeskolen også støtte fra institusjonalismen. Det er liten tvil, ifølge Robert $\mathrm{O}$. Keohane, om at stater endrer politikk når de inngår allianse med andre (Keohane 1989: 2). Størst betydning har frykten for å bli stemplet som "gratispassasjer». Skandinavias USA-dreining kan derfor forstås som et resultat av issue-linking: et ønske om å vise solidaritet med andre fordi et eventuelt svik i fellesskap man selv trenger kan slå tilbake på en selv, men da på andre saksområder - eller issues - på et senere tidspunkt (Axelrod \& Keohane 1993: 89). Risiko- og byrdefordeling i kriger der Skandinavia har få interesser, som i Afghanistan, Irak eller Syria, øker forventingen om amerikansk «assurance» rundt neste sving, enten man er fullt eller bare delvis medlem av NATO (Wallmark 2016). Denne resiprositets-tankegangen kommer også til uttrykk på andre måter. Skandinaviske småstater blir ofte, til tross for sine individuelle forskjeller (Saxi 2011) ofte ansett som «flinkeste gutt i klassen» når institusjonelle reformer settes i verk. Av frykt for amerikansk alenegang har særlig Norge og Danmark vært blant de ivrigste i å støtte tiltak som øker USAs nytteverdi i NATO (Devold 2002; Heier 2006: 107-110; Rasmussen 2013).

\section{Andre forklaring - idealer og dyre reformer}

Men kan «drømmen om Amerika» også skyldes andre forhold? Årsaker som ikke nødvendigvis skyldes økt «tomteverdi», skjev maktbalanse eller institusjonell forvitring. 
Hvilken betydning har det liberale verdigrunnlaget på 1990- og 2000-tallet hatt? Idealer som har legitimert en rekke militære intervensjoner etter den kalde krigen, og som har blitt brukt som «brekkstang» $\mathrm{i}$ arbeidet med noen av de mest dramatiske forsvarsreformene i moderne tid. Hovedargumentet i denne artikkelen er at forsvarsreformene på 1990- og 2000-tallet - med vekt på flernasjonal integrasjon snarere enn selvstendig forsvarsevne - har økt avhengigheten til USA. Avviklingen av nasjonale territorialforsvar til fordel for «alliansetilpassede innsatsforsvar» har riktignok styrket kampen for en liberal verdensorden med menneskerettigheter, rettsstatsprinsipper og demokrati i sin midte. Men satsingen på høyteknologiske nisjekapasiteter, som jagerfly, ubåter, spesialstyrker og etterretningsenheter, har også bidratt til noe annet: en raskere og mer omfattende forvitring av de skandinaviske statenes egne nasjonale forsvarsevne. Dette er først og fremst fordi høyteknologiske nisjekapasiteter bidrar til en dramatisk vekst $i$ småstatenes drifts- og investeringskostnader på forsvarssiden. Dermed blir det umuligå unngå at resten av forsvarsevnen stykkes opp og gradvis fragmenteres.

Dette utviklingen har redusert småstatenes sikkerhetspolitiske handlingsrom fordi avhengigheten til USA tiltar. Skandinavisk politikkutforming utenfor «egen stuedør» blir dermed mer lydhør overfor hva USA selv måtte mene eller finne på. Med en Trump-administrasjonen som forfølger «America first doktrinen» vil fortsatt «harde maktmidler» bli brukt. Potensielt sett vil de også være et kjærkomment tilskudd til skandinaviske småstater som ligger nærme Russland. Men hvorvidt det amerikanske tilskuddet vil tjene skandinaviske interesser, eller inngå i et større strategisk partnerskap med Russland, gjenstår å se. Signalene fra innsettingsavtalen til USAs nye president sender uansett tvetydige signaler: vel så viktig som opprettholdelsen av «gamle allianser» med kollektive institusjoner og bindende konsultasjonsmekanismer legger Trump-administrasjonen vekt på «nye allianser mellom gamle fiender».

\section{Idealet om et utvidet sikkerhetsbegrep}

Et utgangspunkt for å forstå dreining kan være fremveksten av et «utvidet sikkerhetsbegrep» i vestlig tenkning. Med Sovjetunionens oppløsning og spredning av «svake stater» kunne verken Bush- eller Clinton-administrasionene definere transatlantisk sikkerhet bare ut ifra statssikkerhet eller forsvar av eget territorium. Nær sagt alle de liberale demokratiene i Vest-Europa, Nord-Amerika, Australia og New Zealand, mente at nye utfordringer - som internasjonal terrorisme, organisert kriminalitet og spredning av masseødeleggelsesvåpen - også måtte inkludere samfunnssikkerhet. For å trygge stabiliteten i sentrum måtte derfor kritiske samfunnsfunksjoner i periferien sikres (Kjølberg \& Jeppesen 2001: 33), spesielt i stater som stod på randen av borgerkrig. Men som del av samfunnssikkerheten økte også betydningen av menneskelig sikkerhet. I så vel Skandinavia som i Vesten for øvrig ble idealet om «retten til liv og personlig trygghet» brukt for å legitimere intervensjoner i andre land (Holzgrefe \& Keohane 2003). Unnfallenhet under massakrene i blant annet Rwanda (1994) og Srebrenica (1995) virket drivende på en utvikling der humanitære intervensjoner og nasjonsbyggingsprosjekter ble iverksatt i stor stil. Krigene i Kosovo (1999), Afghanistan (2001-2014) og Libya (2011) er eksempler på dette. USA og de skandinaviske 
landene var, sammen med Canada og de fleste andre vestlige stater, pådriverne (Fukuyama 2004; Wivel 2005; Suhrke 2011; Jahn 2013).

\section{«Out-of-area» eller «out-of-business»}

Med basis i det «utvidete sikkerhetsbegrepet» og operasjonaliseringen i FN-doktriner som Protection of Civilians (1999) og Responsibility to Protect (2005) vokste det også frem et større behov for å sette makt bak kravene (Kjeksrud et al. 2016). Europeiske styrker kunne ikke lenger ses på som «nasjonale nødvergeinstrument» i en av verdens fredeligste og mest velstående regioner. Snarere måtte militære styrker forflytte seg raskere og over lenger avstand for å bli en mer naturlig del av Vestens utenrikspolitiske «verktøykasse» (Wivel 2005). Borgerkrigene på Balkan især ble en øyeåpner for så vel Norge som Sverige og Danmark; landenes forsvarsstyrker var håpløst utdaterte og hang fremdeles fast i den kalde krigens statiske og territorielle tidsalder (Børresen et al. 2004: 211-216). Med dette økte også den amerikanske irritasjonen over Europas manglende evne til å ta ansvar for egen sikkerhet, selv utenfor egen «stuedør» (Gates 2011; Lundestad 2003: 250-4). Alvoret ble enda tydeligere etter terrorangrepene mot USA 11. september 2001: «Years of cuts in defense spending and failure to meet pledge after pledge to improve European military capabilities has left some Americans with doubts as to what our allies could realistically contribute» (Lugar 2002). Skulle Europa håndtere et «utvidet sikkerhetsbegrep» måtte NATO enten «out-of-area» eller «outof-business», et mantra USA hadde krevd siden starten på 1990-tallet (Liebig 1990; Heier 2006: 35-42; Hallams 2010: 54-65).

\section{«Punching above its weight»}

Gjennom ulike USA-initierte reformprogrammer i NATO (Defence Capability Initiative (1998), Prague Capability Committment (2002), Smart Defence (2009) og Connecting Force Initiative (2012)), har europeiske medlemmer og partnere fått mer kraft i sine nasjonale forsvarsreformer. I stedet for å duplisere styrkene fremelskes Europas komparative fortrinn (Albright 1998). På den måten har amerikanske ideer og programmer hjulpet europeiske småstater «opp og stå» rent militært - i det som norske politikere velger å kalle et «alliansetilpasset forsvar» (FD 2008: 52; FD 2012, 15; FD 2016, 22). I tråd med Pentagons visjoner om Full Spectrum Dominance og teknologisk overlegenhet hentet fra foint Vision 2010 og foint Vision 2020 får skandinaviske styrker et spisset og mer ekspedisjonært preg (Heier 2006: 53-5). Sofistikerte nisjekapasiteter fra Norge, Sverige og Danmark kan lettere inngå i komplementære «styrkepakker» under operativ kommando av USA, i det som ofte har blitt til «løse koalisjoner». Reformene har på den ene siden bidratt til å gjøre Norge og Danmark til middelsstore militærmakter i NATO, spesielt fordi små luft-, sjø og landmilitære enheter har fått bedre strategisk forflytningsevne, taktisk mobilitet, reaksjonsevne og egenbeskyttelse. Sammen med Sverige kan de skandinaviske landene på kort varsel sette inn spesialstyrker, jagerfly og etterretningsenheter til Afghanistan, Libya, Irak og Syria. Tross landenes beskjedne størrelse betegnes særlig Norge og Danmark som «countries that punches above its 
weight» i Washington D.C. og Brussel. Småstatene har også blitt interessante samarbeidspartnere for regionale stormakter som Storbritannia, Tyskland, Polen og Frankrike, land med mellom 40 og 80 millioner innbyggere (Villaume 2006). Ofte betegnes også Norge og Danmark som land med bredest kontaktflate inn i amerikanske sikkerhets-, forsvars- og etterretningsmiljøer (Heier 2006: 89).

\section{Økte kostnader - mer sårbarhet}

På den annen side har de samme reformene også bidratt til en rivende kostnadsvekst på drifts- og investeringssiden (Agrell 1990; Diesen 2011; Gulichsen 2015). I møtet med andre og mer presserende samfunnsoppgaver har omstillingen ført til kronisk underfinansiering av egen forsvarsevne (Bogen \& Håkenstad 2015: kap. 5; Agrell 1990). Den viktigste årsaken er at de økonomiske kostnadene som fulgte med «transformasjonen» på 2000-tallet ikke var tilpasset småstatsbudsjetter som også skulle avsette penger til den nasjonale forsvarsevnen. Det betyr at stadig flere av de skandinaviske styrkene raskt vil komme under såkalt «kritisk masse». Med dette menes at norske, svenske og danske militæravdelinger vil begynne å forvitre straks de settes under litt press. Kritisk kompetanse på helt sentrale områder er nemlig i dag avhengig av enkeltpersoner - ikke robuste kampavdelinger som inngår i et samtrent «system-av-systemer» med dedikerte ledelses-, manøver- støtte- og logistikksystemer. Dermed skal det svært få avvik til - for eksempel fra en fredelig «normaltilstand» i Stockholms skjærgård eller i vernesonen rundt Svalbard - før konsekvensene blir uforholdsmessig store. Selv mindre episoder eller hendelser vil dermed raskere bli «sikkerhetisert» (Wæver 1995), rett og slett fordi en liten krise som måtte være under oppseiling plutselig føles mer alvorlig for «rikets sikkerhet». Små og tilsynelatende uskyldige situasjoner i møtet med russiske styrker vil følgelig raskere kunne dukke opp på den «sikkerhetspolitiske radaren» i Oslo, Stockholm eller København. Dermed vil også forsvarsdepartementene, deres militære sjefer og tilhørende etterretningsorganisasjoner få «friere tøyler»; det blir lettere få gjennomslag for strategier som raskere tyr til «ekstraordinære tiltak», som for eksempel det fremskutte «terskelforsvaret» i Finnmark. Rett og slett fordi «grunnleggende nasjonale interesser» oppleves å stå på spill, og fordi statene selv ikke har lenge igjen før egne styrker kollapser. Slike hensyn oppleves ofte som mer dramatiske enn uforutsette hendelser på «mykere» eller «mindre farlige» politikkområder som miljø, helse eller samferdsel. Dermed legitimeres også bruken av mer offensive strategier - på et tidligere tidspunkt enn det som ellers ville vært nødvendig i et mulig kriseforløp.

\section{Skandinavisk vakuum og avhengighet}

Basert på denne utviklingen kan USA-dreiningen forstås som et resultat av uforutsette konsekvenser fra en tid da forholdet mellom USA og Russland var godt, og hvor det var fornuftig å satse på nisjer. Det var også fra en tid der skandinaviske idealer la mer vekt på menneskelig enn statlig sikkerhet. For Norge, Sverige og Danmark er imidlertid den skandinaviske lavspenningspolitikken tidløs (Holst 1967). I tråd med den «nordiske balansen» fra den kalde krigen har norske, svenske og danske myndigheter fortsatt 
interesse av å holde stormaktene på en armlengdes avstand, i hvert fall så lenge som mulig. Spesielt for å unngå unødig spenning og stormaktsrivalisering i egne nærområder. Med avviklingen av territorialforsvarene blir imidlertid evnen til å føre en tradisjonell beroligelsesstrategi overfor Russland vanskelig. Dette er rett og slett fordi den sikkerhetspolitiske handlefriheten som muliggjør en slik selvstendig linje er borte. Dermed kan det hevdes at det i stedet oppstår et maktvakuum - som på invitasjon fra skandinaviske myndigheter nødvendigvis må fylles med amerikanske snarere enn med russiske styrker. Men med dette trekkes også norske, svenske og danske myndigheter raskere inn i et klassisk sikkerhetsdilemma mellom øst og vest. Ikke fordi Russland frykter et mer selvhevdende Skandinavia, men fordi økt amerikansk nærvær langs egne grenser oppleves truende sett med russiske øyne.

En skandinavisk politikk som erstatter egen utilstrekkelighet med sterkere amerikansk tilstedeværelse kan dermed føre til mer uforutsigbarhet, spesielt i måten Russland vil reagere på. Årsaken er at egne svakheter gjør det vanskeligere for utenriksdepartementene i Oslo, Stockholm og København å fremme politiske løsninger som passer inn i den tradisjonelle «lavspenningspolitikken», med dialog og brobygging. I følge den amerikanske statsviteren Robert Kagan er USA generelt sett mer opptatt av «... coercion rather than persuasion, emphasizing punitive action over inducements to better behaviour, the stick over the carrot» (Kagan 2003: 4). Sitatet er grovkornet men det understreker en generell trend: småstater som Norge, Danmark og Sverige foretrekker oftere forhandling, kompromiss og tilbakeholdenhet fordi de verken har militær slagkraft, troverdig avskrekkingsevne eller tradisjoner for «kanonbåt-diplomati» slik stormakter gjerne har (ibid.: 5).

\section{Avslutning}

«Drømmen om Amerika» er ikke annerledes for Skandinavia enn for andre europeiske land. Det er de samme rammebetingelsene som gjelder: Overgangen fra nasjonale til flernasjonale forsvarsløsninger «... er en del av en større internasjonal trend som har fått sterkt gjennomslag i praktisk talt alle Nato-land og hos alle Nato-partnere den siste 20-årsperioden» (Petersson 2011: 124). Denne trenden er i stor grad definert av USA (Heier 2006: 34-55). Men de innenrikspolitiske veivalgene som ble gjort på 1990- og 2000-tallet kaster mer lys over utviklingen: Ønsket om å styrke menneskerettigheter, rettsstatsprinsipper og demokrati med et «alliansetilpasset forsvar» har redusert det politiske handlingsrommet til småstatene i nord. Når statssikkerhet igjen kommer på moten er derfor Skandinavia tvunget til å legge seg tettere opp til USA. Men som de tre eksemplene i innledningen illustrerer: omdreining skjer i dag raskere, den er mer omfattende, og den skjer på et tidligere tidspunkt i et kriseforløp. Grunnen er at avhengigheten til USA i dag er større enn under den kalde krigen - da i hvert fall Norge opererte med en «holdetid» på mer enn en måned (Gjeseth 2011: 17, 40, 54), og hvor Sverige hadde verdens fjerde største luftforsvar.

En skandinavisk småstatsstrategi som fra slutten av 1990-tallet brukte militære nisjekapasiteter som sikkerhetspolitisk «døråpner» i Washington D.C. og Brussel kan dermed ha vært en kortsiktig strategi. Den fungerte bra så lenge USA selv var 
interessert i flernasjonalt samarbeid, og brukte tid på å lytte til «gamle allierte» på det europeiske kontinent. Men den kan ha svekket de skandinaviske landenes egen sikkerhet om det viser seg at den nye Trump-administrasjonen blir mer opptatt av Russland enn av dem selv. Frykten for et russisk fait accompli i egne nærområder - uten at Trump-administrasjonen vil løfte en finger om det ikke tjener dem selv - giør paradoksalt nok at «drømmen om Amerika» kommer nærmere. Men på godt eller vondt?

\section{Litteraturliste}

Agrell, Wilhelm (1990) Det velorganiserade nederlaget. Stockholm: Manifest forlag.

Albright, Madeleine (1998): «The Right Balance Will Secure NATO's Future». Financial Times 07.12.1998.

Andrén, Nils (2009) «The Nordic Balance: An Overview», The Washington Quarterly, 2 (3): 49-62.

Axelrod, Robert \& Robert O. Keohane (1993), «Achieving Cooperation under Anarchy: Strategies and Institutions» i David A. Baldwin (red.) Neorealism and Neoliberalism. The Contemporary Debate. New York: Columbia University Press (85-115).

Beate, Jahn (2013) «The Tragedy of Liberal Diplomacy», fournal of Intervention and State-Building, 2 (1): $88-106$.

Bogen, Olav \& Magnus Håkenstad (2015) Balansegang. Forsvarets omstilling etter den kalde krigen. Oslo: Dreyers forlag.

Bush, George (1989) «A Europe Whole and Free», tale i Mains, Vest-Tyskland, 31. mai. Tilgjengelig på http:// usa.usembassy.de/etexts/ga6-890531.htm. Lesedato: 16.11.2016.

Børresen, Jacob, Gullow Gjeseth \& Rolf Tamnes (2004) «Allianseforsvar i endring». Norsk forsvarshistorie, bind 5. Bergen: Eide forlag.

Devold, Kristin Krohn (2002) tale til Institutt for forsvarsopplysning, februar.

Diesen, Sverre (2011) Fornyelse eller forvitring. Forsvaret mot 2020. Oslo: Cappelen Damm.

Eriksen, Knut Einar (1999) «Norge og Norden - samarbeid og kollisjon» i Chris Prebensen (red.) NATO 50 år. Norsk sikkerhetspolitikk gjennom 50 år. Oslo: Den norske atlanterhavskomite (132-149).

FD [Forsvarsdepartementet] (2008) «Et forsvar til vern om Norges sikkerhet, interesser og verdier», St.prp.nr. 48 (2007-2008), Oslo, 28. mars.

Forsvarsministeriet (2016) «NATO trækker i arbejdstøjet», Pressemelding. Tilgjengelig på http://www.fmn.dk/ nyheder/Pages/forsvarsminister-fra-bruxelles-nato-traekker-i-arbejdstoejet.aspx.

Fukuyama, Francis (2004) State-Building: Governance and World Order in the 21st Century. Ithaca, NY: Cornell University Press.

Gates, Robert (2011) «The Security and Defence Agenda (Future of NATO)», tale i NATOs hovedkvarter i Brussel. Tilgjengelig på http://archive.defense.gov/speeches/speech.aspx?speechid=1581. Lesedato: 16. 11.2016.

Gjeseth, Gullow (2011) Landforsvarets krigsplaner under den kalde krigen. Bergen: Fagbokforlaget.

Gulichsen, Steinar (2015) «Prinsipper for en bærekraftig forsvarsøkonomi», FFI Rapport nr. 1432, Kjeller: FFI. Tilgjengelig på https://www.ffi.no/no/Rapporter/15-01432.pdf. Lesedato: 16.11.2016.

Hallams, Ellen (2010) The United States and NATO Since 9/11. London: Routledge.

Heier, Tormod (2006) Influence and Marginalization. Norway's Adaptation to US Transformation Efforts in NATO, 1998-2004. Oslo: Unipub.

Holst, Johan Jørgen (1967) Norsk sikkerhetspolitikk $i$ strategisk perspektiv, bind 1. Oslo: NUPI.

Holzgrefe, J.L \& Robert O. Keohane (2003) Humanitarian Intervention. Ethical, Legal and Political Dilemmas. Cambridge: Cambridge University Press.

Kagan, Robert (2003) Of Paradise and Power. New York: Alfred A. Knopf.

Keohane, Robert O. (1989) International Institutions and State Power: Essays in International Relations Theory. Boulder: Westview Press.

Kjeksrud, Stian, Alexander W. Beadle \& Petter H. F. Lindqvist (2016) «Protecting Civilians from Violence», FFI og NODEFIC, Oslo/Kjeller. Tilgjengelig på: https:/www.ffi.no/no/Publikasjoner/Documents/ Protecting-Civilians-from-Violence.pdf.

Kjølberg, Anders \& Morten Jeppesen (2001) «En modell for sikkerhetstenkning etter den kalde krigen», FFI-rapport nr. 4595, Kjeller: FFI. Tilgjengelig på: http://www.ffi.no/no/Rapporter/01-04595.pdf. 


\section{Tormod Heier}

Lugar, Richard G. (2002) «NATO's Role in the War on Terrorism», tale i NATOs hovedkvarter, Brussel, 18. januar. Tilgjengelig på http://avalon.law.yale.edu/sept11/lugar_001.asp. Lesedato: 16.11.2016.

Liebig, Alexander (1990) «NATO: 'Out of Area or Out of Business'?», Executive Intelligence Review, 17 (50): 33-35.

Lundestad, Geir (2003) The United States and Western Europe Since 1945. Oxford: Oxford University Press.

Mackinder, Halford J. (1962) Democratic Ideals and Reality. New York: Norton and Company.

Mehta, Aaron (2016) «Sweden, US Agree to Closer Defence Collaboration», Defence News, 8. Juni. Tilgjengelig på: http://www.defensenews.com/story/defense/policy-budget/policy/2016/06/08/sweden-usrussia-hultqvist-intent/85573150/.

Morgenthau, Hans (1948) Politics Among Nations. The Struggle for Power and Peace. Boston: McGraw Hill.

Petersson, Magnus (2011) «En skandinavisk transformasjonsbølge» i Tormod Heier (red.) Nytt landskap - nytt forsvar. Oslo: Abstrakt forlag (101-131).

Rasmussen, M.V. (2013) «Punching above Its Weight: Denmark's Legitimate Peripheral Participation in NATO's Wars» i Janne Haaland Matlary \& Magnus Petersson (red.) NATO's European Allies. Military Capability and Political Will. London: Palgrave Macmillan (262-278).

Saxi, Håkon Lunde (2011) «Dansk og norsk forsvarspolitikk etter den kalde krigen: Mellom geopolitikk og strategisk kultur», Internasjonal Politikk, 69 (1): 37-57.

Rasmussen, Anders Fogh (2011) «Statement by NATO Secretary General Anders Fogh Rasmussen on Libya», Pressemelding nr. 36, Brussel, 27. mars. Tilgjengelig på http://www.nato.int/cps/en/natolive/news_71808. htm. Lesedato: 16.11.2016.

Schogol, Jeff (2016) «Marines may head to Norway as U.S.-Russia relations grow colder». Marine Times, 10.10.2016. Tilgjengelig på https:/www.marinecorpstimes.com/articles/marines-may-rotate-throughnorway. Lesedato: 16.11.2016.

Suhrke, Astrid (2011) When More is Less. The International Project in Afghanistan. New York: Columbia University Press.

Sveriges Riksdag (2016) Samforstandsavtal om vardlands stød. Sammensatta utrikes- och forsvarsutskottets betenkande 2015/16:UFøU4. Tilgjengelig på https://data.riksdagen.se/fil/CC7A890D-585C-4472-94F723AA9169A7E8. Lesedato: 16.11.2016.

Thucydides (1951) The Peloponnesian War. New York: Random House.

Villaume, Poul (2006) «Aktivisme - eller tilpasning?». Politiken 24.09.2006. Tilgjengelig på http://politiken.dk/ debat/kroniken/premium/ECE177630/aktivisme---eller-tilpasning/. Lesedato: 16.11.2016.

Waltz, Kenneth (1979) Theory of International Politics. Reading, Mass.: Addison-Wesley.

Walt, Stephen M. (1987) The Origins of Alliances, Itacha, N.Y.: Cornwell University Press.

Wæver, Ole (1995) «Securitization and desecuritization» i Ronnie D. Litschutz (red.) On Security. New York: Columbia University Press (46-86).

Wivel, Anders (2005) «Between paradise and power: Denmark's transatlantic dilemma», Security Dialogue, 36 (3): 417-421.

Wallmark, Hans (2016) «Sveriges møyligheter at søka medlemskap i NATO», Interpellasjon 2016/17:6, Stockholm 13. oktober. Tilgjengelig på https://www.riksdagen.se/sv/webb-tv/video/interpellationsdebatt/ sveriges-mojligheter-att-soka-medlemskap-i-nato_H4106. Lesedato: 16.11.2016.

\section{Om forfatteren}

Tormod Heier (PhD) er oberstløytnant i Hæren og forsker ved Forsvarets høgskole. Han har bakgrunn fra blant annet Etterretningstjenesten og Forsvarsdepartementet $\mathrm{og}$ ha de senere år redigert en rekke bøker om norsk og alliert forsvars- og sikkerhetspolitikk. Korrespondanse: theier@fhs.mil.no. 